\title{
Transitions Between Tiers in U.S. News \& World Report Rankings of Colleges and Universities
}

Received (in revised form): June 14, 2002

\section{Dennis R. Ridley}

Dr. Dennis R. Ridley is the Director of Institutional Research and Planning at Virginia Wesleyan College. His areas of specialization include assessment and program evaluation, educational psychology, and higher education research.

\section{Nuria M. Cuevas}

Dr. Nuria M. Cuevas is the Director of Institutional Effectiveness and Assessment at Norfolk State University, VA. Her areas of expertise include institutional effectiveness and measurement and evaluation theory.

\section{Alexei G. Matveev}

Alexei G. Matveev is a doctoral candidate in Higher Education at the College of William and Mary, Williamsburg, VA, with interests in economics, institutional effectiveness, assessment, and statistics.

\begin{abstract}
Timely information regarding academic reputation and competitive edge is often sought from rankings of colleges and universities in the United States, such as are published by the U.S. Neres \& World Report. This paper examins the issue of whether time spent paying attention to these rankings is well spent in the likely pay-off of reaching the immediate goal of higher rankings. To state the issue another
\end{abstract}

way, we ask: how often do changes in rankings occur? Do they frequently tend to improve? Are positive movements in rankings as likely as negative movements? The studies examine the two categories of national liberal arts and Southern regional universities. The research finds sufficient stability within the rankings to justify a somewhat cautious view regarding efforts to improve an institution's rankings. Several issues concerning such efforts are examined in light of these results.

\section{Keywords: \\ stability of college rankings, institutional reputation}

Timely information regarding academic reputation and competitive edge is critical 
to the functions of institutional advancement. One source of such information consists of rankings of colleges and universities in the United States, and a prominent example is published by the U.S. Newes \& World Report (USNWR). Each year the USNWR rankings serve as a guide to college applicants and their parents. As such, these rankings, it is believed, are taken quite seriously. Decisions affecting innumerable academic careers are at stake, and from the standpoint of competitive higher education institutions, these stakes are high. Since colleges and universities recognize the impact that these published rankings (and many others) can have, the leaders of many of these institutions are eager to improve their standing. Thus, presidents, institutional advancement and admissions officers, and others pay particularly close attention to the rankings and the criteria that influence them, undoubtedly aspiring to influence their own institutions in a way that will have a positive impact on the ratings and the benefits that will follow.

\section{Perspectives from the Literature}

Rankings of academic quality have been a part of the US academic scene for approximately 100 years. ${ }^{1}$ Today, national rankings have become widely read and fundamentally a big business, with revenue from the various news-magazines that publish college rankings and guidebooks topping $\$ 16,000,000$ annually in sales alone. ${ }^{2} \mathrm{~A}$ major contributor is USNWR, which began publishing reputational rankings of US colleges with a survey of college presidents in 1983 and has become the "gold standard" of the ranking business. ${ }^{3}$ Furthermore, the influence of the USNWR and other rankings is likely to increase because of their ready availability on the Internet. ${ }^{4}$

USNWR ranking has long been the subject of widespread criticism for its use of "soft data," questionable or (some say) meaningless criteria, and arbitrary weighting schemes, and for its technical difficulties. ${ }^{5}$ Ostensibly, the editors of USNWR have gone out of their way to change their methodology on an annual basis in order to mollify their college critics. $^{6}$

Arguably, a major reason why USNWR rankings have become so immensely popular and influential is not because they have been useful for college choice but primarily because colleges and universities have aggressively used them to promote themselves. ${ }^{7}$ The tier rankings are important for college and university administrators because they partly define the institution's niche market; influence the perception of the institution by prospective students, which affects enrollments and operating budgets; and serve as a guide to the institution's strategic planning. ${ }^{8}$

The January 1997 issue of State Policy Reports highlighted a relationship between school quality ratings and the return on investment that states receive for their support of public higher education, thus making the suggestion to tie college funding to ranking status. ${ }^{9}$

Monks and Ehrenberg analyzed the changes in USNWR ranking for the top national universities and liberal arts colleges and found that "a change in rank does have a significant influence on admissions outcomes and institutional pricing decisions ... these in turn will have an impact on the institutions' future rank." ${ }^{10}$ Similarly, Bednowitz found that changes in USNWR ranks are highly 
related to admissions outcomes at MBA programs. ${ }^{11}$

One might ask why study changes in ranks? One perspective is that, “... since we may change our methodology from year to year, we do not invite readers to track colleges' annual moves in the rankings." 12 Overall, 60 percent of students find news-magazine college rankings to be not at all important, 30 percent cite rankings as somewhat important, and 11 percent rate them as very important in their college choices. ${ }^{13}$ Studies find that rankings are primarily used by better-off students from collegeeducated families. The students who lack comprehensive guidance from schools and families are not using the rankings by news-magazines in their college choice decision making. ${ }^{14}$

Alternatively, the rankings issues of the news-magazines sell. Ehrenberg keenly noted that " ... it is the change in the numerical rankings of institutions near the top of each institutional category, as well as the changes in the quartile rankings of some lower ranked institution from year to year that sells lots of copies of [USNWR] magazines." ${ }^{15}$ Bednowitz, in his study of the impact of USNWR rankings on business schools, found that the recruiting choices of employers are not statistically related to a program's ranking for a given year. ${ }^{16}$ Rather, employers react exclusively to changes over time.

Bednowitz further concludes that “ ... students may not be behaving in their best interest by reacting to single-year changes in rank ... Based on employers' behavior, it makes more sense for a student to take a longer term view and attend a school which has been highly ranked for many years ..., even if that school is not currently ranked highly." ${ }^{, 17}$ Ehrenberg finds that colleges' shifts in the rankings are a reflection of the competitiveness of the market segment where the institutions operate. $^{18}$

In reviewing perspectives on USNWR rankings, our intent is not to promote or disparage either USNWR or its rankings, but first to better understand the rankings, and secondly to provide additional perspectives in the following studies to help colleges and universities know better how to respond to the realities that the rankings represent.

\section{The Issues Addressed by the Current Study}

\section{Issue 1: Movement in Ranks}

Some would argue that efforts to improve rankings should not be equated with direct improvements in institutions. Others might argue that there are overall benefits that stem from the efforts of USNWR, and dozens of others, to perform a service for consumers. This paper does not deal directly with the issue of whether the time spent paying attention to college rankings is well spent in the sense that that time leads directly to institutional improvements. Rather, the paper deals primarily with the related issue of whether such efforts are well spent in the sense that they are likely to pay off in reaching the immediate goal of higher rankings. To state the primary issue another way, we asked the following questions: how often do changes in rankings occur? Do they frequently tend to improve? Are positive movements in rankings as likely as negative movements? This study is not intended to discourage institutional efforts but rather to provide an accurate picture of how much movement, whether rising or falling, has occurred historically. Such 
information is the best guide on how much movement, positive or negative, to expect in the future. It was hoped that the answers to these and related questions would help to guide institutions in deciding whether their efforts to improve their rankings are likely to succeed.

\section{Issue 2: Determining Institutional Location within Tiers}

A secondary but related issue that emerged as this article was being reviewed is: how well can an institution establish its specific standing with respect to the ranks? This issue arises because the USNWR ranks are categorical assignments called "tiers" (see discussion of tiers below). For all but the highest category, USNWR does not reveal an institution's exact location within those categories. This issue relates to the primary issue to the extent that an institution requires more specific information about its rank location in order to calculate whether concerted efforts might successfully raise its tier status. Equally, such specific information might signal when concerted efforts would be required for an institution to successfully maintain its current tier assignment.

\section{Method}

\section{Issue 1: Movement in Ranks}

This section summarizes the methods used for both the national liberal arts and the Southern regional categories of institutions to address movement in ranks. While studies of both groups were standalone studies, the second was conducted later as a replication study. The two studies used very similar methods in order to insure that comparisons could be made between the two studies. For convenience and ease of presentation, the following method description makes reference only to the national four-year liberal arts colleges. Exceptions that apply to the second study will be mentioned later in the paper.

At the outset, we undertook a study of the rankings for six previous years in the USNWR for nationally ranked four-year liberal arts colleges. Six years of rankings (1996 through 2001) gave the possibility of movement over five years: 1996-7, 1997-8, 1998-9, 1999-2000 and 2000-1. Colleges could stay the same over all five years or change. If they changed, they could change up or down repeatedly in several possible combinations. (Note that the years named 1996-2001 or years of reference are dated one year after the date of the actual issues in which the rankings appear.)

Although the 2002 rankings were available well in advance of the 2001 ASHE national conference for which this paper was originally prepared, we decided not to include those results for the liberal arts college part of the study. Examination of the 2002 results suggested that a noticeable shift in methodology had occurred. Part of the change was the addition of dozens of institutions that had previously participated in other categories of USNWR rankings. Our impression was that formerly distinct categories of institutions had been conflated in the new rankings. On the other hand, the USNWR explanation referred simply to a redefinition of the category of "liberal arts college" to be one that awards "at least half its degrees in the liberal arts" (up from a benchmark of 40\%), so that the list had "changed somewhat."19 Whether that bland description was accurate or understated the change is difficult to debate without undertaking a new study of 
the latest ratings. We have not had the leisure to undertake such a study. Future study should and doubtless will extend into the special circumstances and findings associated with the 2002 and later rankings of liberal arts colleges and other categories.

Since the method used depends upon the definition and composition of "tiers," it will be useful to provide a description of the tiers for the national liberal arts colleges. As already stated, during the years studied USNWR used the Carnegie Foundation definition of "liberal arts college" as colleges that offered at least 40 percent of their courses in the liberal arts. ${ }^{20}$ "National" in contrast with "regional" has reference to the geographic area from which the college attracts new students. As regards tiers, in each category of institution USNWR defines four levels or tiers of institutions, from tier 1 or the highest rank to tier 4, the lowest. As described by USNWR, tier assignments depend upon weighted scores derived from measures dealing with retention, faculty resources, admissions selectivity, financial resources, graduation rates, and alumni giving. ${ }^{21}$ For the years studied (except the latest used, or 2001), tiers for the national liberal arts colleges consisted of about 40 institutions in each tier, going up slightly to allow tied ranks in tier 1, the only tier in which the ranks within the tier are published. In the latest round, USNWR allowed the number of colleges in tier 1 to rise to 51, possibly due to greater numbers of tied ranks, while reducing the number in tier 2 . With that exception, the numbers for the years studied have stayed relatively constant at roughly 40 in each tier. Barring the infusion of many new institutions as happened in the 2002 rankings, which are not studied here, this description might lead one to expect little net change from year to year over all the colleges among all 162 national liberal arts colleges. However, it was necessary to use the following empirical approach to answer our research question of how much change was typical for any given college.

The method used involved entering the names of all colleges and their tier assignments (1-4) for each year into a spreadsheet. For tier 1 assignments only, we made entries of the unique institutional rank (1-n, where $n$ was the lowest rank), as published by USNWR. Sorting the spreadsheet by college and by year within colleges afforded an opportunity to identify cross-tier movements. Most of the findings reported below stem from these simple steps and the various counts and other calculations that they facilitated.

\section{Issue 2: Determining Institutional Location within Tiers}

The issue concerning the importance of determining an institution's location within its tier grew out of the review process. Thus we have formulated an approach that is exploratory and is limited for the present to USNWR data for national liberal arts colleges. Further development, to attain the best balance of accuracy and utility, would be desirable.

The method devised to address this issue depended on accessing tabular data, published by USNWR in its "Best Colleges" issue in the national liberal arts section. In addition, the section of the issue that describes how the rankings are created was also vital because it included the weights assigned to various types of data. The objective of this method was to extract this information for members of two adjacent tiers (3 and 4), and attempt 
to replicate, as nearly as possible, the USNWR tier assignments for these institutions. As pointed out by an anonymous reviewer of a previous version of this paper, USNWR does not provide all the data forming the basis of the rankings; however, the issue becomes whether the method reveals sufficient accuracy to give a reasonable assessment of the position of the institution within the tier.

Having the goal of accurate estimation of within-tier position, the method outlined here is intended as conceptual and nontechnical guidance toward that goal. (Follow-up questions regarding specific steps may be referred to the first author.) From the two tiers (3 and 4), 32 colleges were selected at random, with equal representation from each tier. Tabular data published by USNWR for these institutions were placed into a spreadsheet along with the weights reported by USNWR. To overcome the problem of different units, a routine conversion into "standard scores" allowed the different variables to be combined (after appropriate weighting) into a single summative score. A few other minor difficulties had to be dealt with, such as the use of scores from two different aptitude tests, the ACT and SAT, and the use of ranges of scores. Approximately 90 percent of the variables, by assigned weight, were converted to standard score equivalents. A weighted sum determined a final summative score.

Finally, a correlation coefficient was calculated to estimate the degree of association between the weighted scores and the correct tier assignment. To apply accurately to the full complement of institutions in the two tiers, the correlation had to adjust for the use of a sample, because the calculation based on a sample contains more error and necessarily underestimates the true degree of association. An appropriate statistical adjustment was made. A high degree of association would validate the use of the constructed or summative measure to estimate approximate within-tier positions. Toward achieving even greater utility while maintaining accuracy, the same method was repeated, using only the two most heavily weighted variables-academic reputation and graduation rate.

\section{Results and Discussion: National Liberal Arts Colleges (Issue 1)}

If one looks at the probability of any changes taking place out of all opportunities for change to have occurred, that value turned out to be 0.14 . In other words, change occurred in 14 percent of the opportunities. Therefore most of the year-to-year comparisons showed no change. The probability of no change from one year to the next was 1.00 minus 0.14 or 0.86 , that is, 86 percent of the opportunities. Further, the probability of a change (0.14) was nearly evenly divided between rising and falling, with the probability of reaching a higher tier in the next being approximately 0.08 and that of declining being approximately 0.07 .

Looking at the institutions, there were 162 represented over the six years. That is only slightly higher than the 160 that would be expected if there were 40 in each tier each year and there were no newcomers. In fact, there were several, but only very few, that appeared fewer than six times. The breakdown is shown in Table 1.

The obvious implication is that, once included among the "Best Liberal Arts Colleges," an institution is likely to stay there. The complementary conclusion is 
Table 1: National liberal arts colleges: Frequency of appearances during a six-year period (1996-2001)

\begin{tabular}{lcl}
\hline Appearances & $\begin{array}{l}\text { Frequency } \\
(\mathbf{N}=\mathbf{1 6 2})\end{array}$ & $\begin{array}{l}\text { Cumulative } \\
\text { percentage }\end{array}$ \\
\hline 6 & 157 & 96.9 \\
5 & 0 & 96.9 \\
4 & 1 & 97.5 \\
3 & 0 & 97.5 \\
2 & 2 & 98.8 \\
1 & 2 & 100.0 \\
\hline
\end{tabular}

that movement within the 160 or so best is extremely slow and difficult. There were 91 institutions that showed no movement at all over six appearances. This conservatism is shown most of all in tier 1 , which is partly due to the "ceiling" effect; simply put, tier 1 institutions cannot rise to a higher tier. However, tier 4 membership is also conservative, even though the institutions making up that tier are at most risk of falling off the "best colleges" list completely.

Since the bottom three tiers are not ranked, it is difficult to determine the average movement per institution per year over the five years of possible change. Such study fell outside the resources available for the current study.

Fortunately, there was a shortcut to making a relevant estimate. The shortcut was to calculate the average change in rankings within tier 1 between 1996 and 2000. The average change per year over four years of the 40 or so institutions in tier 1 turned out to be 1.94 positions.

\section{Movement Over All Six Years}

It is interesting to note an average change in ranking of 1.94 positions over the years studied. This represents only 5 percent of the range between ranks of 1 and 40 . Inspection of the rankings from year to year showed that they were tightly confined, going up or down at most only a few places. Two colleges with the greatest upward movements, from the 1996 to the 2000 rankings, moved up 10 places. A third college moved up seven positions.

If movement happened similarly within the other three (unranked) tiers, we may expect that movement between tiers might be fairly rare. However, when considered over all six years, movement up or down was not particularly rare. Considering the movement from tier 4 to tier 3, there were 49 institutions that had the opportunity to make that movement during at least one year in the period 1996-2001. Of these 49 institutions, there were 19 that did move up at least once. This number was equivalent to approximately 39 percent. It should be borne in mind that this rate is fairly low on a per year basis. Over six years (five transitions), the average upward shift, per institution per year, was slightly less than 8 percent.

However, even if movement was not particularly rare, one needs to know whether the overall upward movement tends to be balanced by downward movements. In other words, can the overall movement pattern be described as "zero sum," with upward movement of some colleges balanced and compensated for by the downward movement of other or (in many cases) the same colleges. One relevant observation was the following. While 19 colleges moved from tier 4 to tier 3, 19 made the reverse trip from tier 3 to tier 4.

There were 62 institutions in tier 3 that had the opportunity to move up to tier 2 between 1996 and 2001. There were 27 that actually moved up. Again, such 
movement was not unusual. The percentage of upward movers over all six years was 43.5. On a per year basis, that is slightly more than 8 percent per year. There were also 28 that moved down from tier 2 to tier 3, suggesting again a "zero sum" situation. Again, many of the same colleges that moved up also moved down.

\section{A Comparison of Institutions' Relative Movements Up or Down}

The number of institutions that had multiple movements (both up and down) was examined. Of the 68 institutions which experienced any transitions from one tier to another, those transitions could be divided into four categories. The first category consisted of simple reversals; that is, the ranking went up in one year and down in a subsequent year, or vice versa. There were 25 (40.3 percent of the "movers") that fell into that category. The second category was of institutions with 1.5 transitions; that is, there was a shift (up or down) that was cancelled out by the reverse shift and then reinstated by a third shift back to the original tier. There were eight transitions falling into that category (12.9 percent). Third, there was one "double reversal," consisting of a change from tier 3 to 2 and back to 3 , followed by a shift to 4 and back to 3 . Finally, there were two special cases. One institution was assigned to tier 4, although it had refused to provide data to USNWR. Subsequently the institution rose to tier 1 , and still later fell to tier 2. Finally, one institution experienced a "double slide," from 2 to 3 and then from 3 to 4 . In all, 36 of the 62 institutions (or 58.1 percent) had multiple movements within the six years.

A related question is how much the institutions that rose (or fell) in their tier assignments actually changed in rank relative to other institutions. Since USNWR does not publish detailed ranks except within tier 1 , the existing data do not permit an easy answer to that question. However, we may turn again to tier 1 data (limited to 1996-2000) to find the answer to an analogous question at that level. To address this question, we created an artificial division within tier 1 between institutions with a rank higher than or equal to 20 (i.e. 1-20) and those with a rank lower than 20 (i.e. 21-40). Let us call them tier $1 \mathrm{~A}$ (most premier) and tier 1B (less premier). If we look for movement between the two new groups, we can measure the change in rank of those colleges that moved in either direction. It turns out there were only two institutions that rose from tier $1 \mathrm{~B}$ to tier $1 \mathrm{~A}$; one moved from rank 21 to 11 and another rose from 23 to 18 . Only one college made the reverse movement from tier $1 \mathrm{~A}$ to tier $1 \mathrm{~B}$, moving from rank 18 in 1996 to rank 23 in 2000.

\section{Results and Discussion: Southern Regional Universities (Issue 1)}

This part of the article replicates the methods that were applied to the national liberal arts colleges. This section presents the results of a study of the rankings for the six years $(1996,1998-2002)$ in the USNWR for Southern regional universities at master's level. In this category, the researchers were not able to obtain the 1997 rankings from the area university and public libraries, or from the USNWR website. However, having six years of rankings provided a convenient basis of comparison between the findings for the two categories of institutions. Six years of rankings gave the possibility of five cross-tier movements: 1996-8, 1998-9, 
1999-2000, 2000-1, and 2001-2. Although the time span differed slightly from the study of national liberal arts colleges, since we lacked one year of data for Southern regional universities, we opted to maintain comparability in the number of transitions. The aim was to expand the scope of study beyond one category, increasing the generality of findings, despite a less than perfectly parallel selection of years.

During the period of time studied, universities could stay the same over all years or change. If they changed, they could change up or down repeatedly in several combinations. If one looks at the probability of any changes (up or down) taking place out of all opportunities for change to have occurred, the value turned out to be 0.19 . In other words, change occurred in 19 percent of the opportunities. Therefore most of the yearto-year comparisons showed no change. The probability of no change from one year to the next was 1.00 minus 0.19 or 0.81 , that is, 81 percent of the opportunities. The probability of a change (0.19) was approximately equal between rising and falling, with the probability of reaching a higher tier being 0.11 and that of declining being 0.09 .

Table 2: Southern regional universities (master's level): Frequency of appearances during a six-year period $(1996,1998-2002)$

\begin{tabular}{lcc}
\hline Appearances & $\begin{array}{l}\text { Frequency } \\
(\mathbf{N}=\mathbf{1 4 3})\end{array}$ & $\begin{array}{l}\text { Cumulative } \\
\text { percentage }\end{array}$ \\
\hline 6 & 111 & 77.6 \\
5 & 11 & 85.3 \\
4 & 1 & 86.0 \\
3 & 0 & 86.0 \\
2 & 2 & 87.4 \\
1 & 18 & 100.0 \\
\hline
\end{tabular}

Looking at the institutions, there were 143 represented over the six years. Again, the majority of institutions appeared in the rankings all six years. The breakdown of results appears in Table 2.

Out of 111 institutions that appeared over all six years, 47 institutions showed no between-tier movement at all over six appearances. The conservatism is shown most of all in tier 1 , which is partly due to a "ceiling" effect; as noted earlier, tier 1 institutions cannot rise to a higher tier.

Since the bottom three tiers are not ranked, it is difficult to determine the average movement per institution per year over the five years of possible change. As with the examination of the liberal arts category, such a study fell outside the resources of time available for the current study. We used a shortcut to making a relevant estimate. The shortcut was to calculate the average change in ranks within tier 1 between 2000 and 2002. The average change in rank turned out to be 2.30 positions; that is, only about one-third of a position difference from the comparable finding for national liberal arts colleges.

A finding of 2.30 positions is interesting because it represents only 6 percent of the range between ranks of 1 and 38. The greatest upward movement, from the 2000 to the 2002 rankings, was 11 positions. The greatest downward movement was nine positions.

\section{Movement Over All Six Years}

If movement happened similarly within the other three (unranked) tiers, we may expect that movement between tiers should be fairly rare. However, when considered over all six years, movement up and down was not particularly rare. Considering the movement from tier 4 to tier 3 , there were 41 institutions that had 
the opportunity to make that movement during at least one year during the period 1996-2002. Of these 41 institutions, 21 moved up at least once. This number is approximately 50 percent.

However, even if movement was not particularly rare, one needs to know whether the overall upward movements tend to be balanced by downward movements. In other words, can the overall movement pattern be described as "zero sum," with upward movement of some colleges balanced and compensated by the downward movement of other or (in many cases) the same colleges? One relevant observation was the following: while 21 institutions moved from tier 4 to tier 3, 21 also made the reverse shift from tier 3 to tier 4.

There were 51 institutions in tier 3 that had the opportunity to move up to tier 2 at least once between 1996 and 2002. Of these, there were 18 that moved up at least once. So such movement was not unusual. However, there were also 16 that moved down from tier 2 to tier 3 at least once. Many of the same institutions that moved up also moved down.

There were 50 institutions in tier 2 that had the opportunity to move up to tier 1 at least once between 1996 and 2002. Of these, there were 16 that moved up at least once. However, there were also 10 that moved down from tier 1 to tier 2 at least once between 1996 and 2002.

\section{A Comparison of Movement Between the 1996 Rankings and the 2002 Rankings}

If we look at the movement of the 111 institutions that appeared both in 1996 and 2002, 75 institutions did not change their tiers, 25 moved up, and 11 institutions moved down.
There were 31 institutions that were in tier 4 who had, theoretically, the opportunity to move up between the 1996 and 2002 rankings. One university moved to a different category (national universities). There were seven institutions that moved from tier 4 to tier 3 . There were two institutions that moved from tier 4 to tier 2. This number (i.e., nine institutions from 4-to-3 and 4-to-2) is approximately 30 percent.

If membership within the "Best Colleges" list is conservative, changing only rarely, and a relatively small number rise in rank, it is possible that the overall movement pattern within the list can be best described as "zero sum." That is, upward movement of some universities is balanced and compensated for by the downward movement of other universities. For example, while the seven universities moved from tier 4 to tier 3 , six universities made the reverse trip from tier 3 to tier 4.

Again there were 31 institutions in tier 3 that had, theoretically, the opportunity to move up between 1996 and 2002. Two universities moved to a different category (national universities). One institution dropped from the USNWR rankings. There were six universities that moved up between 1996 and 2002. Further, there were three universities that moved down from tier 2 to tier 3 between 1996 and 2002 .

Again there were 31 institutions in tier 2 that had, theoretically, the opportunity to move up between 1996 and 2002. Three universities changed their categories: two joined the national universities category, and one moved to the comprehensive colleges category. Ten universities moved from tier 2 to tier 1 between 1996 and 2002. Further, there 
were two universities that moved down from tier 1 to tier 2 between 1996 and 2002.

There were 32 institutions in tier 1 . Six institutions changed their categories: three moved to the liberal arts colleges category, two moved to the national universities category, and one moved to the comprehensive colleges category. To further analyze movement in tier 1 , we created an artificial division within tier 1 between institutions with a rank higher than or equal to 15 (i.e., 1-15) and those with a rank lower than 15 (i.e., 16-32). Let us call them tier $1 \mathrm{~A}$ (most premier) and tier 1B (less premier). If we look for movement between the two new groups, we can measure the change in rank of those colleges that moved in either direction. It turns out that out of 24 institutions that stayed in tier 1 over all six years, only one institution moved from $1 \mathrm{~B}$ to $1 \mathrm{~A}$, while one institution made the reverse movement from tier $1 \mathrm{~A}$ to $1 \mathrm{~B}$.

\section{Results and Discussion: Determining Institutional Location within Tiers (Issue 2)}

As stated earlier, the second issue addressed determining an institution's position within its tier. Although the study was exploratory and limited in scope to national liberal arts colleges, the results were highly encouraging.

The method outlined above yielded a correlation coefficient of +0.87 between the weighted summative scores and the correct tier assignments for each institution. When we repeated the procedure for the two highest weighted variables, academic reputation and graduation rate, we found a comparably high correlation coefficient of +0.83 . On a practical level, the two most important variables together comprise most of the critical information, the remainder providing, for the most part, statistically redundant information. Thus, for "quick and dirty" estimates, an institution can determine fairly readily whether its actual (unrevealed) within-tier position lies in the upper third, middle third, or bottom third of the tier just by comparing its values on the two most important variables with the same variables of other institutions in the tier.

\section{Implications and Future Research}

As stated earlier, our intent in this article was not to promote or disparage either USNWR or its rankings, but to better understand the rankings in order that colleges and universities might learn better how to respond to the realities that the rankings represent.

The information presented in this paper provides one important source of guidance for institutions wishing to improve their rankings. In general, there is sufficient stability within the rankings to justify a somewhat cautious view toward efforts to improve an institution's rank. Many will conclude that a probability between 0.08 (national liberal arts colleges) and 0.11 (Southern regional universities) of rising in any given year, does not offer much encouragement. At the same time, the finding bodes well for those institutions that happen to be content with their rankings because they are as high as they can be or as high as college representatives expect them to become. Such institutions can afford perhaps to relax their efforts in regard to raising or maintaining their high status as far as these rankings are concerned. However, this general conclusion, while defensible in light of 
the results, should not be construed as discouraging the efforts of those institutions that would like to improve their rankings. Neither should the results be construed as offering an excuse for complacency among those institutions that happen to be content with the rankings that they already possess.

Before embracing those conclusions, two cautions should be observed. First, it is exceedingly important for an institution to determine its approximate rank within the tier to which it has been assigned. Without such information, it is impossible to determine whether efforts to improve are likely to bear fruit within less than, say, 10 years. The point that institutional changes affecting rankings (or any significant institutional changes, for example, those required to meet institutional effectiveness goals) can take a long time should come as no surprise. Our point here is that the time required to change in tiers can be greater or less depending on position relative to other institutions. It could be argued that the institutions that showed the most movement (often multiple times, both up and down) had ranks that were close to the tier margins or borders. If so, the majority of institutions that did not move probably had a longer "distance" (in ranks) to move before a change in tier status would become manifest. By such reasoning, it is important to know approximately where an institution ranks (i.e., in detail, not merely in its tier assignment) as useful information when attempting to raise an institution's rank. Equally, it is impossible to know without estimating those rankings whether the institution is at risk of moving backward in tier assignment or falling off the list altogether.
To address this first caution, this article makes a case that within-tier position can be estimated with sufficient accuracy to provide practical guidance. For tier 1 institutions (i.e., those having the least need for this information), ranks within the tier are provided and easily retrieved. It is institutions within the other three tiers that need the most guidance. As a practical matter, a "quick and dirty" estimate can be made using two measures that have the largest weights: academic reputation and graduation rate. These variables comprise sufficient information to allow reasonably accurate judgments as to whether the institution occupies a position toward the top, in the middle, or toward the bottom of its assigned tier. Thus, by following simple procedures using readily accessible data, an institution will possess critical information. Again, this information bears upon the issue of whether expending effort to attain higher tier status makes sense in terms of the likelihood of achieving success.

A second caution is that institutions would do well to reflect upon what they would do if the rankings did not exist at all. They should consider whether the efforts expended to improve or maintain rank or tier assignment are substantially the same as the efforts that would be expended if USNWR were not in this business. If the answer to that question is that the efforts would be substantially the same, then it might make better sense for the institution to use scarce resources to pursue the goal of improving its rank. Those efforts could more easily be defended to the degree that they merely duplicated the efforts that would be expended if there were no rankings to drive them. 
Despite apparently strong arguments that may be made against college rankings (some of which were cited earlier in this article), there is a perspective from which doing the work required to move upward in ranks is essential business. For example, as mentioned above, two of the most important factors that go into the calculation of ranks by USNWR are academic reputation and graduation rates. Indeed, colleges and universities with higher ratings of academic reputation and higher graduation rates also have higher ranks, whether those ranks have been provided by USNWR or another newsmagazine. It is difficult to imagine that a higher education institution would be unconcerned about either variable. Therefore, as we pursue our missions, we will strive to enhance our institutions' academic reputations and create environments in which students will persist and reach their degree goals. If these efforts are effective, they should eventually influence college rankings. The high weights assigned by USNWR to these variables merely reflect the importance of key elements of quality higher education.

From this perspective, the greatest yield for improving rankings will come from paying attention to that which we already recognize as critical. There is a large and growing literature that deals with enrollment management-and with good reason. Effort invested in that area is extremely worthwhile, and also reaps the greatest benefits to colleges when they are compared, as inevitably they will be, with other institutions of higher learning.

Even more critical are academic reputation and the educational quality that supports a strong reputation. It is not difficult to name some areas of concern that can make a huge difference in academic reputation, including a faculty reward system that provides appropriate incentives and sufficient time, apart from teaching, to assure that teacher-scholars can let their lights shine throughout the academic world; a salary structure that is capable of recruiting productive, first-rate new faculty members; creative programming to foster lively cultural and intellectual exchange as part of the daily life on campus; and many more ideas along those lines. As a final comment, institutions that would raise the bar for progression to higher levels of academic reputation (and, as a byproduct, higher ranks) must become what we will call "webwise." The Internet is fast becoming an indispensable tool for both scholarship and for establishing an institutional presence that cannot be ignored. A fruitful avenue of investigation (already begun by these authors) $)^{22}$ concerns how institutions can harness the Internet for maximum benefit. We look forward to future participation in these vital investigations and discussions.

\section{References}

1. T. J. Webster (2001), “A principal component analysis of the U.S. Newes \& World Report tier rankings of colleges and universities." Economics of Education Review, 20, 3, pp. 235-44.

2. Patricia M. McDonough, Anthony L. Antonio, MaryBeth Walpole, and Leonor X. Perez (1997), "College rankings: Who uses them and with what impact." Paper presented at the Meeting of American Educational Research Association, Chicago, IL, March.

3. Ibid.; Ronald G. Ehrenberg (2001), "Reaching for the brass ring: How the U.S. Newes o w World Report rankings shape the competitive environment in U.S. higher education," Cornell Higher Education Research Institute, Working Paper No. 17.

4. Webster (2001), "A principal component analysis," op. cit.

5. Ibid.; Bruce Gottlieb (1999), "Cooking the school books: How U.S. Neres cheats in picking its best American colleges," Article posted by Slate on August 31, 1999: <http://www.slate.com/crapshoot/ 
99-08-31/crapshoot.asp>; Nicholas Thompson (2000), "Cooking the school books (yet again): The 'U.S. Neres' college rankings gets phonier and phonier," The Washington Monthly, 14 September, also on <http://slate.msn.com/id/89623/>; B. Ann Wright (1992), "A little learning is a dangerous thing: A look at two popular college rankings." College Board Review, 163, pp. 6-16.

6. McDonough et al. (1997), "College rankings" op. cit.; Anne Machung (1995), "Changes in college rankings: How real are they?" Paper presented at the Meeting of the Association for Institutional Research, Boston, MA, May 28-31; Robert J. Morse and Jersey Gilbert (1995), "Publishers' perspectives: Magazines," in R. Dan Walleri and Marsha K. Moss (Eds.), New Directions in Institutional Research: No. 88. Evaluating and Responding to College Guidebooks and Rankings, Jossey Bass, San Francisco, CA, pp. 91-108.

7. Anne Machung (1998), "Playing the rankings game," Change, 30, 4, pp. 12-17.

8. T. J. Webster (2001), “A principal component analysis," op. cit.

9. Hal Hovey (1997), "The quest for quality in higher education," State Policy Reports, 15, 2, pp. 2-24.

10. James Monks and Ronald G. Ehrenberg (1999), "U.S. Newes \& World Report's college rankings: Why they do matter," Change, 31, 6, p. 10.

11. Ian Bednowitz (2000), "The impact of the Business Week and U.S. Neres \& World Report rankings on the business schools they rank," Cornell Higher Education Research Institute, Working Paper No. 6.

12. Robert J. Morse and Samuel M. Flanigan (2002), "America's best colleges 2002: How we rank schools." Quotation found on March 13, 2002 at <http://www.usnews.com/usnew/edu/college/ rankings/about/02cbrank.htm>.

13. Morse and Gilbert (1995), "Publishers' perspectives," op. cit.

14. Ibid.

15. Ehrenberg (2001), "Reaching for the brass ring."

16. Bednowitz (2000), "The impact of the Business Week and U.S. Newes \& World Report rankings.”

17. Ibid., p. 31 .

18. Ehrenberg (2001), "Reaching for the brass ring," op. cit.

19. U. S. Neres and World Report (2001), "America's best colleges 2002 edition,” p. 79.

20. U. S. Neres and World Report (2000), "America's best colleges 2001 edition, p. 39.

21. Morse and Flanigan (2000), "America's best colleges 2002," op. cit. pp. 28-30.

22. Alexei G. Matveev, Dennis R. Ridley, and Nuria M. Cuevas (2002), "Becoming web smart: An exploratory study of Internet Visibility of Virginia's college and university websites," online publication sponsored by the Virginia Assessment Group and Virginia Association for Management Analysis and Planning Virtual Conference 2002, archive located at <http://www.brcc.edu/research/vagvamap2002.html>.

\section{Acknowledgement}

E. Charmaine Berina, of Virginia Wesleyan College, is acknowledged and thanked for her assistance with an earlier version of this paper.

\section{Practitioner's Perspective}

The authors express skepticism that efforts to improve an institution's ranking in U.S. Neres will actually yield the desired outcome. Experience at two institutions at or near the top of the rankings tells me they are correct. Yet it doesn't follow that inattention is an acceptable stance, since the outcomes could be worse.

Even at the top, the rankings matter. During the years I worked at Princeton, our ranking fluctuated as U.S. Neres toyed with its formula. Some years we stood at the very top of the national universities; other years we placed third or even sixth. We had not changed in substantive ways, nor had our competitors. But invariably in years we fell out of first place, some number of admitted students would turn us down, saying they preferred to attend the first-ranked school. Then as now, the rankings distracted students from choosing on the basis of their perceived fit with an institution or its program. At Princeton, we didn't change our program to suit the rankings, but we made double sure we were reporting accurately and, like many 
other schools, we lobbied U.S. Neres to improve its methodology in ways that suited our sense of what should matter.

Changes in the ranking formula are only one of three ways an institution's position shifts from year to year. Colleges' individual performance on the various indices can change, as can the performance of our competitors. Given that we directly control neither our competitors' performance nor the formula itself, it seems prudent to do whatever we usefully can to improve our own performance.

Changes that may prove useful in the rankings ought to be considered in light of their real value to the institution. If a change would be both true to the institutional mission and potentially advantageous in the rankings, why not make it? The institution's ranking may not improve; it may stay the same or even worsen, but even in the worst case it will worsen less than if the change had not been made.

At Wesleyan University, we have sought to improve our performance on indices where an improvement would coincide with our sense of academic purpose or institutional need. We have not changed primarily for the sake of the rankings, but knowing that a change has the potential to improve our scores on key indices has spurred us onward. During the period the authors studied, Wesleyan improved its six-year graduation rate, its student-faculty ratio, and the proportion of alumni who give, among others. These changes benefited the institution and its students. They also improved our performance on key indices measured by U.S. Neres. How was our rank affected? Wesleyan remained consistently in the top tier of national liberal arts colleges, but its numerical ranking fluctuated into and then out of the top 10. The reason: our peers were changing too, and so was the formula for the rankings. But we almost certainly fared better than we would have had we done nothing, and we got some good work done for the University in the meantime. 